\title{
TI.119.1
}

\section{Final Report of the InCommon Deployment Profile Working Group}

- PDF: DPWG-FinalReportofthelnCommonDeploymentProfileWorkingGroup.pdf

- Text: DPWG-FinalReportofthelnCommonDeploymentProfileWorkingGroup.txt

\section{More Information}

\begin{tabular}{|c|c|}
\hline Repository ID & TI.119.1 \\
\hline Persistent URL & http://doi.org/10.26869/TI.119.1 \\
\hline Title & Final Report of the InCommon Deployment Profile Working Group \\
\hline Authors & 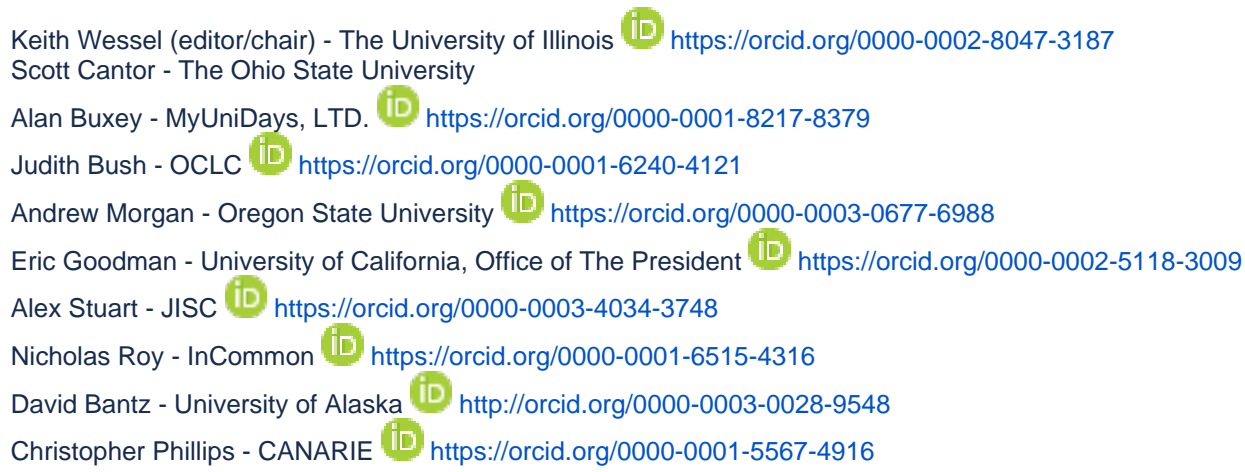 \\
\hline Sponsor & Incommon Technical Advisory Committee (TAC) \\
\hline \multicolumn{2}{|l|}{ Review } \\
\hline Status & Preserve \\
\hline Publish Date & February 14, 2019 \\
\hline DOI & 10.26869/TI.119.1 \\
\hline \multicolumn{2}{|l|}{ Signature } \\
\hline Deprecated & No \\
\hline \multicolumn{2}{|l|}{ Future Review } \\
\hline \multicolumn{2}{|l|}{ Supersedes } \\
\hline Format & PDF, Text \\
\hline \multicolumn{2}{|l|}{ Related Docs } \\
\hline Development Location & https://spaces.at.internet2.edu/x/tw6MBw \\
\hline IP Framework & CC BY 4.0 \\
\hline Subject Tags & federation \\
\hline Notes & \\
\hline
\end{tabular}

